\section{Thymectomy in myasthenia gravis}

Two papers consider thymectomy. Gronseth and Barohn et al. (p. 7) review evidence from controlled studies of thymectomy and note that whereas some reports show benefit of the procedure, none of the trials was randomized and all were limited by multiple confounding variables. They conclude that the benefits of thymectomy for autoimmune MG have not been established. A Task Force of the MG Foundation of America (p. 16) reports recommendations for clinical research standards in the evaluation of thymectomy for MG. - The accompanying editorial by Kissel and Franklin (p. 3) notes that these clinical standards require validation, but points out their value in addressing the many unanswered questions about optimizing treatment for MG. Kissel and Franklin conclude by emphasizing the need for a randomized trial of thymectomy (as well as other treatments) for MG.

Neonatal brachial plexus palsy Brown et al. (p. 24) studied the motor skills and motor unit physiology of 16 children with neonatal brachial plexus palsy (NBPP) in comparison with matched controls. They found evidence for impaired motor unit activation in NBPP patients with poor motor skills. They postulate that defective motor programming results in a form of apraxia. Rollnik et al. (p. 112) used botulinum toxin to treat disabling arm cocontractions that occurred in six young children with NBPP. After two or three treatments, the disorder did not recur. The accompanying editorial by Noetzel and Wolpaw (p. 5) reviews NBPP and links the two papers to consider the reasons for the prolonged disability of many of these patients.
Carotid endarterectomy in ACAS patients with impaired cognition

L.C. Pettigrew et al. for Asymptomatic Carotid Atherosclerosis study investigators (p. 30) used prospective data on Mini-Mental State Examination (MMSE) scores to determine if carotid endarterectomy improved cognition and whether preoperative MMSE was related to morbidity. Endarterectomy did not change MMSE scores. Moreover, a low preoperative MMSE score increased the likelihood of death.

\section{Transcranial doppler for prognosis in stroke}

Bragoni et al. (p. 35) used TCDmonitored cerebral perfusion during an object recognition task to demonstrate that stroke patients whose flow velocity increased bilaterally (as did that of normal subjects) had a better prognosis than those whose did not.

\section{Is vigabatrin visual loss reversible?}

Two or more antiepileptic drugs cause visual loss. Johnson et al. (p. 40) performed follow-up studies in 13 patients with visual defects from vigabatrin, after the patients were off drugs for 3 months to 1 year. Visual field loss did not recover, although other visual system abnormalities did improve.

\section{GAD autoantibodies in refractory epilepsy}

Peltola et al. (p. 46) noted that epilepsy was present in over $20 \%$ of patients with the stiff man syndrome who had antibodies to glutamic acid decarboxylase (GAD). They found that such anti-GAD antibodies were present in 8 of 51 patients with refractory lesional epilepsy, but none of 49 patients with generalized epilepsy. The data suggest that autoimmunity could play a role in refractory epilepsy.
MS: Quality of life and disability; effect of stress Nortvedt et al. (p. 51) studied 97 relapsing-remitting MS patients and found that quality of life (by SF-36) correlated with worsening disability (by EDSS) independent of disease activity. - Mohr et al. (p. 55) found that patients with stresses-conflict and disruption in their routine-were more likely to have increases in disease activity (documented by MRI).

In proximal diabetic neuropathy (amyotrophy): Inflammatory lesions

Kelkar et al. (p. 83) studied muscle and nerve biopsies from 15 diabetics with painful, asymmetric proximal neuropathy. Striking inflammatory vascular abnormalities or IgM-complement deposition were noted in many.

\section{Dementia in HSP with spastin mutation}

White et al. (p. 89) studied a family with autosomal dominant spastic paraplegia caused by missense mutation of spastin. Four patients in the kindred had cognitive abnormalities. Autopsy documented hippocampal tau-positive tangles and substantia nigra Lewy body formation. The pathology differed from other tauopathies.

\section{Deep brain stimulation (DBS) for proximal tremor}

A brief communication by Kitagawa et al. (p. 114) documented dramatic benefit of DBS in two patients with severe proximal essential tremor, one with dystonia.

\section{West Nile virus in New York City: Encephalitis; Guillain-Barré syndrome A brief communication by Ahmed et al. (p. 144) and a clini- cal note by Nichter et al. (p. 153) report patients with neurologic disease caused by a virus newly identified in the New York City area. There is reason to expect that outbreaks of this disease will continue to occur.}




\section{Neurology}

July 12 Highlights

Neurology 2000;55;1

DOI 10.1212/WNL.55.1.1

This information is current as of July 12, 2000

\section{Updated Information \&} Services

\section{Citations}

Permissions \& Licensing

Reprints including high resolution figures, can be found at: http://n.neurology.org/content/55/1/1.full

This article has been cited by 2 HighWire-hosted articles: http://n.neurology.org/content/55/1/1.full\#\#otherarticles

Information about reproducing this article in parts (figures,tables) or in its entirety can be found online at:

http://www.neurology.org/about/about_the_journal\#permissions

Information about ordering reprints can be found online:

http://n.neurology.org/subscribers/advertise

Neurology ${ }^{\circledR}$ is the official journal of the American Academy of Neurology. Published continuously since 1951, it is now a weekly with 48 issues per year. Copyright . All rights reserved. Print ISSN: 0028-3878. Online ISSN: 1526-632X.

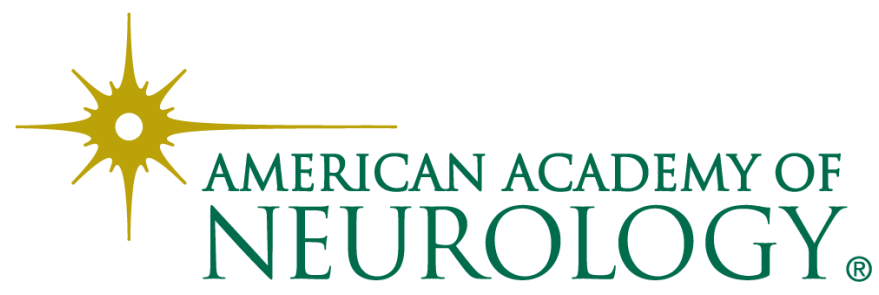

